
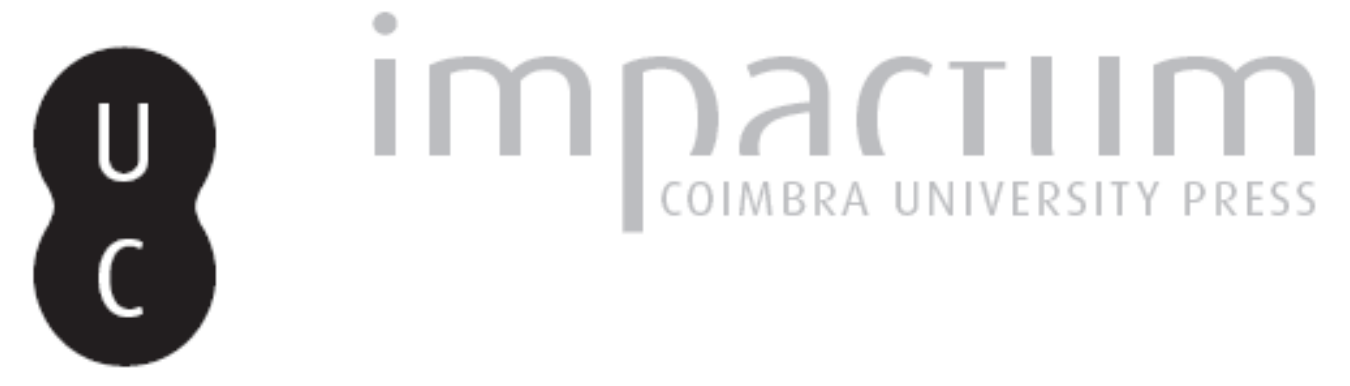

\title{
Em torno do principado de Severo Alexandre: a senatorialização da imagem do príncipe e o campo de Marte
}
Autor(es):
Furtado, Rodrigo
Publicado por: Centro de História da Universidade de Lisboa
URL persistente:
URI:http://hdl.handle.net/10316.2/23844
DOI:
DOI:http://dx.doi.org/10.14195/0871-9527_18_11
Accessed : $\quad$ 26-Apr-2023 13:40:50

A navegação consulta e descarregamento dos títulos inseridos nas Bibliotecas Digitais UC Digitalis, UC Pombalina e UC Impactum, pressupõem a aceitação plena e sem reservas dos Termos e Condições de Uso destas Bibliotecas Digitais, disponíveis em https://digitalis.uc.pt/pt-pt/termos.

Conforme exposto nos referidos Termos e Condições de Uso, o descarregamento de títulos de acesso restrito requer uma licença válida de autorização devendo o utilizador aceder ao(s) documento(s) a partir de um endereço de IP da instituição detentora da supramencionada licença.

Ao utilizador é apenas permitido o descarregamento para uso pessoal, pelo que o emprego do(s) título(s) descarregado(s) para outro fim, designadamente comercial, carece de autorização do respetivo autor ou editor da obra.

Na medida em que todas as obras da UC Digitalis se encontram protegidas pelo Código do Direito de Autor e Direitos Conexos e demais legislação aplicável, toda a cópia, parcial ou total, deste documento, nos casos em que é legalmente admitida, deverá conter ou fazer-se acompanhar por este aviso.

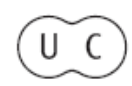



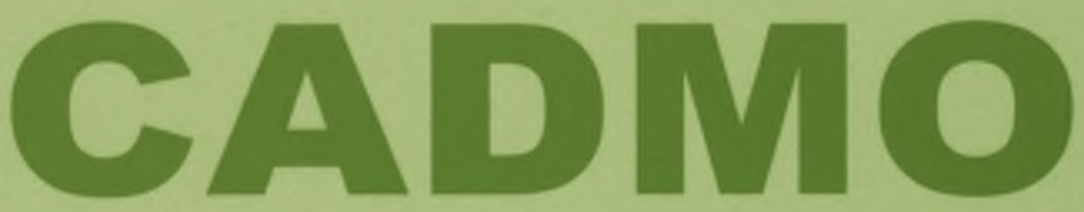

Revista de História Antiga

\author{
Centro de História \\ da Universidade de Lisboa
}

18

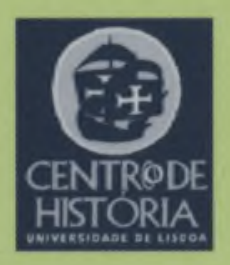

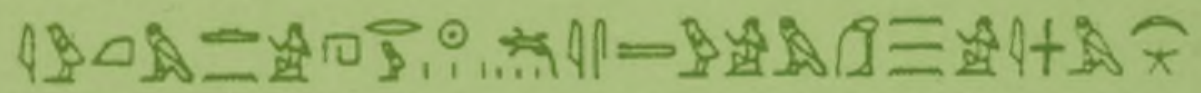

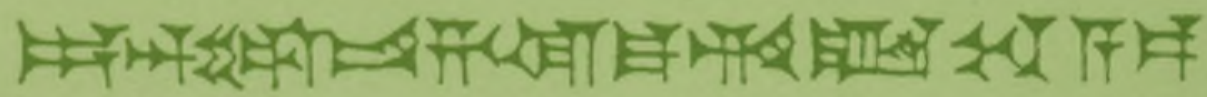

MHNIN AEI $\Delta$ E $\Theta E A ~ \Pi H \Lambda H I A \triangle E \Omega$ 


\title{
EM TORNO DO PRINCIPADO \\ DE SEVERO ALEXANDRE: A SENATORIALIZAÇÃO DA IMAGEM DO PRÍNCIPE E O CAMPO DE MARTE
}

\author{
RODRIGO FURTADO \\ Universidade de Lisboa \\ rcf@fl.ul.pt
}

\section{Resumo}

À primeira vista, Severo Alexandre foi um imperador com sorte. Entre o que podemos reconstruir acerca do seu governo e a imagem transmitida pela tradição historiográfica senatorial verifica-se um quase total desfasamento: de origem síria, um passado como sacerdote de Elagábalo, filho adoptivo, César e herdeiro presuntivo de Heliogábalo, dominado pela mãe, com frouxos resultados militares ao longo do seu principado, acabará assassinado pelas legiões do Reno. Apesar disso, a imagem de Severo Alexandre nas fontes é globalmente positiva. Neste artigo, procurarei avançar uma explicação para este desfasamento, e mostrar que ele encontra as suas raízes no próprio principado de Severo Alexandre. De facto, partindo da intervenção de Severo Alexandre no Campo de Marte, procurarei mostrar que, já na época deste imperador, se tentou construir uma imagem que declaradamente o aproximava da tradição ideológica de matriz republicana e senatorial.

Palavras-chave: Severo Alexandre; Severos; Princeps

\section{Abstract}

In a simple view, Severus Alexander was a lucky emperor. Between his "real" government and the image built by senatorial historians there's an almost insurmountable gap: he was an emperor of Syrian origin with a past as 
Elagabal's priest, he was an adoptive son, Caesar and presumptive heir of Heliogabalus, dominated by his mother, with meager military results during his reign, he'd be slain by his legions on the Rhine. However, Alexander's image is globally positive. In this paper, l'll try to advance an explanation for this gap and to show that it has its roots in Severus Alexander's own reign. In fact, through the analysis of his works in Campus Martius, I intend to demonstrate that, already in his own time, Severus Alexander tried to build an image of himself that rid him of Heliogabalus' political example and brought him closer to the republican and senatorial ideological traditions.

Key-Words: Severus Alexander; Severii; Princeps

Haverá seguramente poucas personagens do século III d. C. tão bem tratadas pelas fontes como Severo Alexandre. À parte Cássio Díon, cujo texto se perdeu, restando-nos apenas algumas escassas linhas transmitidas por Xifilino ${ }^{(1)}$, é Herodiano, também contemporâneo do príncipe, que nos transmite o primeiro retrato alargado do imperador (o seu principado ocupa todo o livro 6 da Historia). Logo no início do relato, Herodiano assegura que ele seria doce ( $\pi \rho \tilde{\alpha} \circ \varsigma)$ e amável

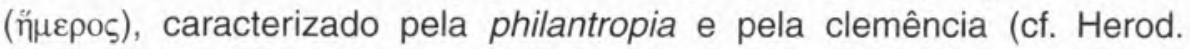
6.1.6-7). A terminar, o historiador garante ainda que, não fora a avare-

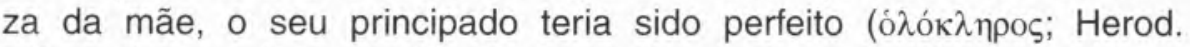
6.9.8). Bem mais tarde, já no século IV, na linha da Kaisergeschichte oficial, Eutrópio e Aurélio Victor referem-se a Severo Alexandre de forma ainda mais favorável, afirmando a sua gloria militar, a sua seueritas na repressão das legiões em revolta, a presença junto de si de Ulpiano como iuris conditor e a pietas singular do príncipe para com a mãe (Eutr. 8.23; Aur. Vict. 24). Aurélio Victor vai mais longe ao considerar que, pela acção de Severo Alexandre, a respublica atingira o seu apogeu. E acrescenta este historiador: "deveu-se a Alexandre o facto de a respublica não ter desmoronado de imediato" (Aur. Vict. 24.7-9). O texto anónimo do Epitome de Caesaribus afirma-o também como bonus reipublicae (Caes. 24.1) e o mais recente Zósimo admite a sua púoıs $\alpha \gamma \alpha \theta \dot{n}$ (Zos. 1.11.2). A fonte que, no entanto, transmite o retrato mais francamente laudatório do príncipe é a Vita Alexandri, da segunda metade do século IV: de todas as biografias imperiais coligidas na Historia Augusta, a mais desenvolvida e a que apresenta o biografado como modelo acabado do optimus princeps é, sem dúvida, a que refere a vida de Severo Alexandre ${ }^{(2)}$. 
É claro que tal benevolência generalizada para com o imperador não impede críticas por vezes severas à sua dependência excessiva em relação à mãe, Júlia Mameia, e à avareza desta e do próprio príncipe (Herod. 6.1.8; Caes. 24.4-5; Julian., Caes. 313, Zos. 1.12.2). Herodiano ocupa também grande parte da sua narrativa com a descrição da óbvia incompetência militar do imperador (e.g. Herod. 6.2.3, $6.3 .1,6.4 .2,6.5 .8-6.7 .10,6.8 .3,6.9 .1-6)^{(3)}$. Mesmo se mantenho reservas quanto ao stemma de fontes apresentado por C. Bertrand-Dagenbach (não julgo suficientemente demonstradas pela autora as dependências estabelecidas entre os diversos textos $\left.{ }^{(4)}\right)$, é evidente que, com Herodiano, também Juliano e Zósimo se fazem eco de uma tradição menos favorável ao imperador; de qualquer modo, os defeitos são justificados por estes autores através da má influência de Júlia Mameia, que era mulher, síria e de uma família onde já outras Augustas haviam mostrado marcada intervenção nos assuntos da respublica (e.g. Herod. 6.1.1, 6.1.4-5, 6.1.8-10, 6.5.8-9, 6.8.3, 6.9.4-5, 6.9.8; Julian., Caes. 313; Zos. 1.12.1-2; cf. Caes. 24.5, SHA Alex. 14.7, 20.3). Contudo, nenhum autor segue a versão de Herodiano acerca dos fracassos militares do príncipe, que caem rapidamente no olvido. Bem pelo contrário, de entre os autores mais favoráveis a Severo Alexandre, Eutrópio, Aurélio Victor e a Historia Augusta chegarão até a insistir no seu grande valor militar (Eutr. 8.23; Aur. Vict. 24.2, SHA Alex. 55). E, com a excepção da referência pontual dos Caesares de Juliano (a única fonte completamente negativa para com Severo Alexandre, mas plenamente enquadrada como texto satírico), todos os autores da Antiguidade admitem as boas qualidades de Severo Alexandre ${ }^{(5)}$ e, de acordo com K. Fuchs e W. Widmer, mesmo Herodiano apenas denigre o valor militar do imperador para poder justificar o seu assassínio e a escolha de Maximino como seu sucessor ${ }^{(6)}$.

Contudo, Severo Alexandre tinha tudo para ser mais um dos «maus príncipes". De origem síria, um passado como sacerdote de Elagábalo (Herod. 5.3.3-5), filho adoptivo, César e herdeiro presuntivo de Heliogábalo $^{(7)}$, dominado pela mãe, com frouxos resultados militares ao longo do seu principado, acabará assassinado pelas legiões do Reno. Acrescente-se a isso o facto de alguns dos homens que estiveram no poder com Heliogábalo terem continuado próximos de Severo Alexandre (Comazon - cf. Dio 79.21.2, SHA Elag. 12.1 - e Zótico - cf. CIL 14.3553), o que todas as fontes silenciam ou referem muito en passant ${ }^{(8)}$; anote-se também que a relação de Severo Alexandre com os pretorianos (certamente os primeiros que o elegeram) se deteriorou rapida- 
mente e culminou no tétrico assassínio de Ulpiano à frente do próprio imperador, incapaz de se fazer obedecer apenas um ano após a sua subida ao poder (Dio 80.2.2); ainda nesse primeiro ano de principado, a plebe urbana deve ter estado em revolta durante três dias pelas ruas da Urbe (Dio 80.2.3); e, vários anos depois, o próprio Cássio Díon, então cônsul, viu-se obrigado a sair de Roma, a conselho de um imperador incapaz de garantir a sua segurança na Cidade (Dio 80.5.1). Pior curriculum uitae seria difícil de construir.

Mas, a ser assim, como é que Severo Alexandre conseguiu transmitir aos seus vindouros uma imagem geralmente positiva, ao ponto de ser referido, pelo menos pelas fontes que chegaram até nós, possivelmente como o melhor dos Severos? Para ensaiar uma resposta, comecemos pela sua muito estranha subida ao poder.

De facto, não é fácil de explicar como é que, em 222, pela primeira vez desde a morte de Calígula, ocorreu o assassínio violento de um príncipe (neste caso, de Heliogábalo) que não arrastou consigo o afastamento da família imperial: acontecera precisamente isso com Nero e o afastamento dos Júlio-Cláudios, com Domiciano e o afastamento dos Flávios e com Cómodo e o afastamento dos Antoninos, e ainda com todos os príncipes que, desde Galba a Macrino, não se tinham conseguido impor por algum tempo nem aos seus sucessores presuntivos. Com Severo Alexandre foi diferente. Quando Heliogábalo foi assassinado, foi escolhido como sucessor precisamente aquele que, pela sua filiação adoptiva e pelo título que já ostentava, era de facto o seu herdeiro designado. Nem com Calígula isso ocorreu - na altura, a escolha dos pretorianos recaiu em Cláudio, que até então estava certamente longe de calcular as suas reais possibilidades de sucessão, numa respublica onde o lugar do príncipe ainda continuava em larga medida por definir. $\mathrm{O}$ que ocorreu em 222 foi, pois, uma originalidade na história de duzentos e cinquenta anos do Império. Uma análise mais profunda avoluma ainda mais a sensação de estranheza.

Herodiano garante que, como em tantas outras ocasiões, partiu dos pretorianos, responsáveis pela morte de Heliogábalo, a iniciativa na escolha do seu sucessor (Herod. 5.8.10). Já a Historia Augusta, numa versão bem mais prestigiante mas certamente mais afastada da realidade, assegura que a responsabilidade na escolha de Severo Alexandre se deveu exclusivamente ao senado, sem mencionar o papel da guarda (SHA Alex. 1.3, 1.6-2.1. Cf. também Eutr. 8.23). De qualquer modo, é certo que não houve propriamente um qualquer interregno. Heliogábalo foi assassinado a 11 de Março de 222 e, de acordo com 
o Feriale Duranum, o dies imperii de Severo Alexandre foi o dia 13 do mesmo mês ${ }^{(9)}$. E, independentemente de quem teve a iniciativa, as principais fontes justificam a escolha de Severo Alexandre procurando contrastá-lo com Heliogábalo até ao limite da verosimilhança. Garantem assim que Severo Alexandre era mais apreciado do que Heliogábalo pela sua modéstia e maior conformidade com a tradição romana. Asseguram também que, entre Heliogábalo e Severo Alexandre, existira alguma animosidade motivada pela maior popularidade deste. Tal facto teria mesmo levado aquele imperador a desejar retirar a Severo Alexandre todos os seus títulos, e até, diziam os boatos, a tentar matá-lo (Herod. 5.8.2, Dio 79.19.1-2, SHA Elag. 13.4-5, Alex. 2.4). Esta vitimização de Severo Alexandre pode ter-lhe granjeado popularidade. E, no entanto, na época em que as fontes situam estes boatos, Severo Alexandre tinha seguramente acabado de ser adoptado por Heliogábalo, que the conferira o título de César ainda em 26 de Junho de $221^{(10)}$. Mais ainda, Severo Alexandre deve ter surgido em epígrafes, logo a partir de meados de 221 , com o título de Imperator $^{(11)}$ e é possível que tenha sido assumido desde a mesma altura como consors imperii, sempre em relação estreita, pois, com o "terrível» Heliogábalo(12). Tudo isto escassos oito meses e meio antes dos acontecimentos que levaram à sua subida ao poder. Não estou a dizer que não tenha existido alguma animosidade entre Heliogábalo e Severo Alexandre. Mas julgo que há uma óbvia tentativa de contrastar e afastar Severo Alexandre de Heliogábalo, procurando resgatar aquele príncipe de uma qualquer conivência ou proximidade a este. De facto, penso que devem ser mais bem estudadas as possibilidades desta inimizade como tópico literário, em conjugação com o que sabemos com toda a segurança acerca das relações políticas entre Heliogábalo e Severo Alexandre.

Para os tempos do principado de Severo Alexandre propriamente dito, a imagem suposta ou as referências explícitas a Heliogábalo nas fontes não desaparecem, mas mantêm-se constantemente como uma espécie de negativo do novo príncipe. Como referi noutro lugar, com Severo Alexandre no poder "ao vestuário excêntrico" de Heliogábalo opor-se-ia agora a sobriedade da veste branca, não dourada e as togas banais (SHA Alex. 4.2, 33.3-4; 34.5; 40.1, 3, 5-11). Socialmente,

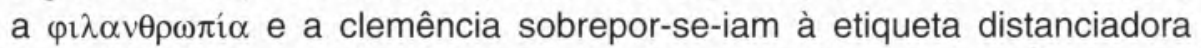
e à crueldade de Heliogábalo (Herod. 6.1.6, SHA Alex. 4.3). À extravagância dos banquetes do anterior príncipe dizia-se ter sucedido a simplicidade (SHA Alex. 34.1, 6-8). As fontes garantem que ele teria afas- 
tado todo o entourage de Heliogábalo (Herod. 6.1.5, SHA Alex. 15.1-2, 34.2-4), e talvez os eunucos (SHA Alex. 45.4-5), o que, mesmo não sendo verdade, deve ter representado um motivo ideológico do novo

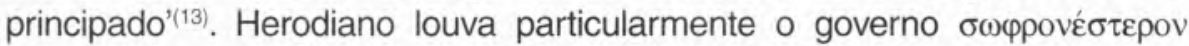

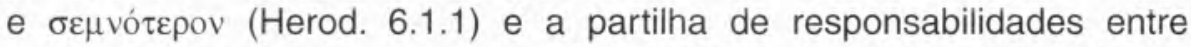
Severo Alexandre e o senado (Herod. 6.1.2, 4). Já a tardia Historia Augusta delicia-se com a iniciativa da cúria, a conceder à pressa todos os títulos imperiais ao jovem príncipe (SHA Alex. 1.4-2.5).

Convenhamos: Severo Alexandre pode mesmo ter sido uma personagem excelente que causou profunda impressão nos seus contemporâneos, a ponto de se constituir à sua volta uma imagem francamente positiva. No entanto, convém voltar a recordar que uma parte dessa imagem não é verosímil: há fontes que atribuem ao senado a escolha exclusiva de Severo Alexandre, quando textos mais próximos dos acontecimentos referem a prioridade da guarda pretoriana; tendem a esquecer as ligações entre Severo Alexandre e Heliogábalo e elas existiram; asseguram a inimizade entre os dois, mas ela está longe de ser confirmada; tendem a negar a presença de algum do entourage de Heliogábalo na corte de Severo Alexandre, e no entanto algumas personagens se mantiveram; afirmam o imperador como uma escolha dos pretorianos e sabemos que o descontentamento da guarda roçou a insurreição logo em 223; afiançam a popularidade do imperador em Roma, mas Severo Alexandre nem a protecção de um cônsul foi capaz de assegurar contra a populaça; chegam a afirmar o valor militar do príncipe, e este deixou de facto muito a desejar.

Não irei procurar debruçar-me sobre todos estes problemas no curto espaço de um artigo. Limito-me a enunciá-los e a intentar uma solução que me parece poder explicar este desfasamento entre a imagem construída de Severo Alexandre e a realidade. Em primeiro lugar, convém contextualizar este desfasamento: Severo Alexandre era herdeiro de uma larguíssima tradição mediterrânea onde a imagem era conscientemente construtora/indutora de sentido - as imagens visual e a verbal, desde os antigos Egípcios ao principado de Augusto, passando pela Acrópole pericleana ou pela Pérgamo dos Atálidas, tinham-se claramente afirmado como prescritivas da realidade, como indutoras mais do que devia ser do que daquilo que realmente era. De algum modo, já no mundo antigo, a imagem visual ou verbal de um indivíduo acrescentava conteúdos e interpretações à realidade, de forma muitas vezes mais sugestiva que a sua presença per se ou que a sua acção governativa. Ora, a imagem de Severo Alexandre desen- 
volvida pelas fontes funciona deste modo: como se, a uma realidade difícil de sustentar se tivesse sobreposto uma outra narrativa dos factos, uma nova imagem que se procurava transmitir, porventura menos "real», mas muito mais eficaz em termos de definição para o presente e de prescrição para o futuro. De facto, mesmo admitindo que haja exagero nesta devoção ao novo príncipe por parte de historiadores de tradição senatorial, há que convir que não se trata apenas de simples exagero: a imagem de Severo Alexandre, não poucas vezes desconforme à realidade, foi explicitamente construída em desfasamento.

Ora, julgo que a chave para a compreensão deste desfasamento reside em dois pormenores já referidos: por um lado (i) na imagem, também ela construída, de Heliogábalo, como pessimus princeps em tudo contrário aos valores e à representação ideológica do "bom romano". De facto, a imagem transmitida de Severo Alexandre não se compreende sem o referente negativo que é Heliogábalo. É assim que, em torno de Severo Alexandre e provavelmente já durante o seu principado, se constrói «uma imagem tópica, que mais do que procurar esquecer a de Heliogábalo, a queria explicitamente afastar e intentava estar nos seus antípodas"(14): por isso todos os elementos que aproximariam Severo Alexandre de Heliogábalo são sistematicamente invertidos ou esquecidos. Não é por acaso que a Historia Augusta insiste que Severo Alexandre «desejava parecer descender da raça romana" e ficava incomodado quando o apodavam de "Sírio"; teria até mandado pintar uma árvore genealógica, na qual se fazia descendente dos irrepreensíveis e republicanos Metelos: ao contrário do que parece ter sido a vontade de Heliogábalo, este desejo de filiação no mundo romano e, mais ainda, no ambiente republicano, é um dos meIhores exemplos de que se procurava, pelo menos como tópico ideológico, esquecer Émesa e a origem síria da família materna do príncipe (SHA Alex. 28.7, 44.3).

Por outro lado, este desfasamento radica (ii) na provável apropriação senatorial da escolha pretoriana de Severo Alexandre. Obviamente o senado do século III não era o da República. No entanto, mantinha-se boa parte do seu poder simbólico(15). E em Roma, continuava a ser o principal órgão de governo. É claro que, em pleno século III, há muito que se deixara de imaginar uma república à maneira antiga, sem príncipe: o imperador era personagem incontornável do sistema político romano há cerca de duzentos e cinquenta anos. Por isso, para o senado o problema que eventualmente se poderia pôr não era o da existência do príncipe, mas o das relações deste com a cúria e 
o do respeito (ou falta dele) pelas imensas prerrogativas e pelos privilégios políticos e sociais do conjunto dos senadores. Augusto, Vespasiano, Tito, Nerva, Trajano, Adriano, Antonino Pio ou Marco Aurélio constituíam (e constituirão) referências, como príncipes que haviam respeitado os mores de matriz republicana. O Panegírico a Trajano de Plínio-o-Moço funciona como bom exemplo do pensamento de um senador em contexto imperial: no fundo, sem que fosse sequer posta em causa a sua existência, o príncipe deveria comportar-se como se a República se mantivesse, cultivando a boa grauitas republicana e os auctores de antanho e rejeitando paradigmas monárquicos de matriz helenística, permitindo aos senadores a colaboração no governo e assumindo-se na cúria como um primus inter pares ${ }^{(16)}$. Ora, tudo isso é louvado em relação a Severo Alexandre ${ }^{(17)}$. Neste sentido, a Historia Augusta mostra os senadores a condenar apressadamente a utilização do nomen dos Antoninos por Heliogábalo (que se chamava Marco Aurélio Antonino) e a oferecê-lo, com ainda mais afã, a Severo Alexandre (SHA Elag. 17.4; Alex. 1.1-2, 7-10). De facto, é possível que tenha sido em torno do nomen Antonino, e da sua calculada, modesta, mas tão "romana" recusa por parte de Severo Alexandre, que primeiro se procurou formatar esta "senatorialização" do novo príncipe, entendendo eu por ela a adequação deste à ideologia de matriz republicana que, assumindo a existência do imperador, o procurava conformar com os mores da Cidade e com o respeito pelas prerrogativas senatoriais. Neste contexto, as moedas assumir-se-ão também como veículo de uma imagem que o príncipe passa a promover e onde as principais uirtutes transmitidas raramente deixam de ser os tradicionais mores republicanos ${ }^{(18)}$ - ressurgem com Severo Alexandre as legendas LIBERTAS, IUSTITIA e PIETAS, à semelhança do que acontecera nas moedas de Vespasiano, depois dos principados de Nero e Vitélio, e nas de Nerva, depois do principado de Domiciano(19). Mesmo sem ruptura familiar, como acontecera naqueles dois casos, Severo Alexandre é assumido como restaurador de uma ordem imperial, que não prescinde mas assume uma imagem (pelo menos uma imagem) de ruptura com o principado anterior. Essa ruptura construída foi o preço a pagar para que Severo Alexandre se mantivesse no poder. E esta ruptura construída com Heliogábalo foi o que garantiu a Severo Alexandre uma imagem globalmente positiva por parte das fontes de tradição senatorial. É do confronto, pois, entre estes dois mundos que, segundo creio, nascerá o Severo Alexandre transmitido à posteridade. 
Não foi, no entanto, apenas a posteriori, entre historiadores tardios, que esta senatorialização do príncipe se formou: de facto, esta conformidade com a tradição imperial de matriz republicana encontra as suas raízes na própria época de Severo Alexandre, de forma muito consciente e calculada. Isso mesmo se verifica nas múltiplas intervenções do príncipe no urbanismo da Urbe. Já noutro lugar procurei mostrar que as intervenções urbanas de Severo Alexandre no Palatino revelam precisamente a tentativa explícita de estabelecer um corte político e ideológico com o principado anterior. A rededicação do Elagabalium, o provável restauro de toda a área deste templo, a importância re-concedida a Júpiter VItor, Victor e/ou Reddux e as intervenções em alguns dos locais tradicionais da colina mostram bem a intenção do novo imperador em se refiliar nos mores tradicionais da Vrbs, em oposição ao que se dizia que Heliogábalo teria procurado fazer. Neste artigo, e por forma a ilustrar precisamente esta senatorialiazação consciente da imagem de Severo Alexandre ainda durante o seu próprio principado, procurarei debruçar-me sobre outra das regiões de Roma onde a intervenção de Severo Alexandre é reveladora da construção de uma nova imagem para o príncipe. Refiro-me ao Campo de Marte.

O Campo de Marte, fora do pomerium da cidade, era, na já longínqua República, o local dos Saepta, onde os comitia centuriata (e, desde o século II a. C., também os tributa) se reuniam para a eleição dos principais magistrados da cidade, e designadamente dos cônsules; era também daí que normalmente partiam os triunfos militares ${ }^{(20)}$. À parte os altares e pequenos templos que deviam abundar em torno do complexo da Largo Argentina(21), é com Pompeio e os primeiros edifícios de entretenimento para a plebe urbana ${ }^{(22)}$, com Júlio César e o seu projecto de edificação dos Saepta (concluídos em 26 a. C.) ${ }^{(23)}$, com o complexo monumental de Agripa $^{(24)}$ (o Panteão(25), as termas ${ }^{(26)}$, o lago e os jardins ${ }^{(27)}$ ) e com o espantoso investimento ideológico de Augusto no seu mausoléu(28), na ara pacis $^{(29)}$ e no horologium ${ }^{(30)}$ que se assiste verdadeiramente à monumentalização desta região da Cidade: constituía-se assim, no espaço do Campo de Marte, o centro ideológico do regime fundado por Augusto. Depois disso, os primeiros imperadores guardarão sempre maior reserva em relação ao local: além de pequenas intervenções e restauros, Calígula patrocinará o 
grande Iseum $^{(31)}$, Nero construirá aí as suas monumentais termas ${ }^{(32)}$ e Domiciano o estádio ${ }^{(33)}$ e o ódeon ${ }^{(34)}$. Não é muito para cerca de cem anos. Só os Antoninos voltarão a investir realmente na região.

Aí reconstruirá Adriano o Panteão, as termas de Agripa e os Saepta lulia( ${ }^{(35)}$. Aí, erguerá Antonino Pio um templo a Adriano ${ }^{(36)}$ e Marco Aurélio uma coluna e provavelmente um altar dedicados a Antonino ${ }^{(37)}$. Também aí levantará Cómodo uma coluna, um altar e um templo em honra de Marco Aurélio e Faustina ${ }^{(38)}$. Tudo entre a ara pacis, o horologium Augusti e as termas de Nero, o Panteão, os Saepta e o Iseum. O facto de, sucessivamente, os templos dedicados aos vários Antoninos se terem situado no Campo de Marte tornou na prática a região numa espécie de santuário dos diui Antoninos, sob a égide do não muito longínquo mausoléu de Adriano, do outro lado do Tibre. É também possível que este regresso em extensão dos Antoninos ao Campo de Marte aponte para os exemplos de Agripa e de Augusto, que eles procuravam assim emular. De qualquer modo, é evidente que este conjunto de imperadores e as suas construções transformaram o Campo de Marte numa das regiões de maior significado ideológico da Urbe, como símbolo do próprio principado; mais ainda, como símbolo de um conjunto de príncipes que as fontes consideravam exemplo privilegiado de comportamento político e de conformidade com os valores tradicionais e republicanos da Cidade.

Apesar de se apresentarem como descendentes destes imperadores, Septímio Severo e Caracala não mostrarão especial interesse pela região, patrocinando apenas, segundo $\mathrm{H}$. Benario, a construção de um porticus Seneri ou o restauro do túmulo de Sula e do Panteão ${ }^{(39)}$. Caberá precisamente a Severo Alexandre a obra de maior envergadura no Campo de Marte desde a época de Cómodo, e a única que perpetuaria o nome de um dos Severos na área ${ }^{(40)}$.

O principal edifício termal da região eram as termas de Nero, que se situavam na proximidade do Panteão, a norte dos jardins de Agripa. Deviam ser termas particularmente populares, continuamente referidas e elogiadas desde pelo menos Marcial até Cassiodoro(41). A sua reconstrução na época de Severo Alexandre está bem atestada por várias fontes e por moedas comemorativas que não deixam dúvidas sobre a importância que este empreendimento deve ter tido na altura. As moedas permitem situar em 227-228 a conclusão das obras, que terão com certeza começado uns anos antes ${ }^{(42)}$. Esta intervenção deve ainda ter sido bastante alargada uma vez que as termas de Nero passaram a ser, a partir de então, conhecidas também como 
thermae Alexandrianae, como começa logo por atestar um papiro de Oxirrinco da primeira metade do século III(43).

Hoje, praticamente nada se consegue vislumbrar destas termas, que estão por baixo de uns seis quarteirões, atrás da Piazza Navona, atravessados pelas Vias della Scrofa e della Dogana Vechia(44). O Palazzo da Madama, mandado construir pelos Medici no início do século XVI, outrora residência de papas, hoje sede do Senado italiano, e a igreja de S. Luigi dei Francesi, também da responsabilidade dos papas Medici, e que hoje constitui a igreja dos Franceses em Roma, utilizam estruturas destas termas. Na parte de trás do Palazzo da Madama existiu uma igreja de S. Salvatore in thermis, nome sugestivo de um edifício hoje desaparecido. Destas termas pouco mais possuímos, e não somos capazes de ter sequer uma planta segura do edifício. De qualquer modo, tratar-se-ia de uma construção de cerca de $200 \times 120 \mathrm{~m}$, ornado pelo menos com colunas de granito cinzento e rosa de Assuão: duas delas foram utilizadas no restauro do pórtico do Panteão de Agripa em 1669 e outras duas, já encontradas em 1934 sob a igreja de S. Luigi dei Francesi, encontram-se desde 1950 na Via di S. Eustachio, na parte exterior da igreja dedicada a este santo. $\mathrm{Na}$ via degli Staderari, a servir de fonte, é possível também encontrar desde 1987 um labrum possivelmente do caldarium das termas ${ }^{(45)}$. As moedas de Severo Alexandre registam um edifício adornado com estátuas e com um pórtico. Pelo menos um medalhão mostra a estátua de uma quadriga, conduzida, sem dúvida, pelo imperador ${ }^{(46)}$.

É certo também que, a partir de Augusto, as moedas de bronze passam em regra a ter as iniciais S.C. (senatusconsultus). Por isso, não estranha que uma das medalhas de bronze da época de Severo Alexandre que mostra estas termas tenha também estas iniciais. Stevenson, no entanto, admite que seja uma espécie comemorativa, emitida por decisão de senado "as a record of gratitude to Alexander for having undertaken and achieved so great a public work»(47). Se assim for, e mesmo sendo estas medalhas meramente de ocasião, cabe vislumbrar nestas obras não apenas o interesse do príncipe pela plebe urbana, mas também o apoio do senado a esta reconstrução.

É provavelmente esta a obra mais impressionante de todo o governo de Severo Alexandre. Por isso foi também esta que deixou uma memória mais duradoura no tempo. É claro que as termas de Nero não eram comparáveis às monumentais termas de Caracala. As de Trajano eram também bastante maiores. Também não sabemos se as termas de Nero estariam em más condições e a necessitar efectiva- 
mente de restauro. Contudo, facto é que não se tratou apenas de um restauro, como o do Coliseu, o do teatro de Marcelo ou o do estádio de Domiciano, também empreendidos por Severo Alexandre. Desta feita, parece ter havido uma autêntica reconstrução e renomeação. Esta renomeação associaria, a partir de então, o nome de Severo Alexandre ao prestigiado Campo de Marte, ao lado de Agripa, Augusto ou dos vários Antoninos. Ao mesmo tempo, sobrepunha esse nome ao de um príncipe pouco querido pela memória historiográfica, alvo ele próprio de damnatio memoriae. Não se perdia assim muito com a substituição: a um príncipe condenado pela tradição senatorial, sobrepunha-se outro apoiado pela cúria - de algum modo, seria talvez possível que, através da reconstrução e sobretudo da renomeação das termas de Nero, se apontasse para a superação simbólica do modelo mais acabado do mau príncipe, de que Heliogábalo teria sido o último representante. O imperador que procurava conformar a sua imagem com os mais tradicionais valores romanos apagava da geografia da cidade o nome de um dos seus mais problemáticos governantes e punha-se claramente em bicos de pés ao lado dos nomes mais prestigiados do Império; ao fazê-lo, mesmo se não explicitamente, era a proximidade ao modelo ideológico supostamente seguido por Heliogábalo que se procurava também esconjurar ${ }^{(48)}$.

E Severo Alexandre não ficaria por aqui. Além da aqua alexandriana, aqueduto que passará a servir as 'novas' termas e que ligava de novo o nome do imperador ao Campo de Marte e às obras de apoio à plebe urbana ${ }^{(49)}$, conta-se ainda, para a época de Severo Alexandre, a construção de uma nova basilica para a Cidade, a ser edificada precisamente no Campo de Marte. E digo "a ser edificada" porque a Vita Alexandri, que é a fonte que refere esta basílica, também admite que ela acabou por não ser concluída (SHA Alex. 26.7). Segundo a fonte, iria situar-se inter Campum Martium et Saepta Agrippiana e teria mil pés de comprimento por cem de largo (cerca de $300 \times 30 \mathrm{~m}$ ), minudências de um texto sobre uma basílica que não chegou a existir. De resto, a serem verdadeiras, estas medidas permitiriam ao edifício projectado por Severo Alexandre ombrear com a maior basílica existente em Roma, a enorme Basílica Úlpia, da época de Trajano, que media $176 \times 59 m$, deixando para trás as antigas mas muito prestigiadas basílicas do velho forum romano, a Basílica Emília (ou Paulli), com ca. $90 \times 27 m$ e a Basílica Júlia, com $101 \times 49 m$. É possível que a construção de uma Basilica Alexandriana tenha estado nos planos de Severo Alexandre. De facto, após a intervenção nas "novas" termas, 
é possível que o príncipe e o seu grupo de apoio tenham planeado continuar a intervir no coração "augustano e antonino" de Roma.

Domaszewski, que tende a duvidar de tudo o que a Vita Alexandri diz, ainda considera que este passo se baseia em Cícero ${ }^{(50)}$. É possível, mas com F. Coarelli não vejo razão para duvidar especialmente da Vita Alexandri, principalmente quando se refere a um edifício não construído. De qualquer modo, há dificuldades difíceis de resolver. $\mathrm{O}$ principal problema é semelhante a um com que já deparei quando, em outra ocasião, procurei avaliar a intervenção de Severo Alexandre no Palatino. O Campo de Marte estava completamente sobrelotado no século III; os últimos espaços vagos deixados no século I d.C. tinham sido ocupados precisamente pelos Antoninos do século II. Por isso, a principal intervenção de Severo Alexandre no Campo de Marte fez-se sobre um edifício que já existia, para o reconstruir e renomear. Todavia, um projecto completamente novo, como o da construção de uma enorme basílica, que voltasse a ligar o nome de Severo Alexandre à região, enfrentaria de certeza problemas de espaço. F. Castagnoli ainda propôs que tal basílica pudesse ter sido planeada para norte do Panteão(51). Contudo, F. Coarelli recusou a proposta por constatar que dificilmente haveria aí terreno livre para um edifício das dimensões que a Vita Alexandri refere.

É claro que a Vita Alexandri é um texto muito tardio, e não é garantido que os seus dados sejam completamente fiáveis. É, no entanto, também possível que estes dados tão precisos tenham figurado em alguma das fontes que a Vita Alexandri diz ter consultado. F. Coarelli aponta uma possibilidade de solução, que me parece razoável: a sul das novas termas alexandrianas havia um jardim (os horti Agrippae) e um lago artificial (o stagnum Agrippae) num local que na Antiguidade tardia foi ocupado pelo porticus Boni Euentus. Este pórtico deve ter acompanhado todo o lado ocidental do lago de Agripa até ao pórtico de Pompeio, a sul(52). Foram encontrados no século XIX pelo menos cinco capitéis coríntios de mármore branco, entre a igreja de S. Maria in Monterone e o Teatro Valle, que devem ter pertencido àquele primeiro pórtico ${ }^{(53)}$. F Coarelli considera a possibilidade de o porticus Boni Euentus ser parte da basílica de Severo Alexandre, que teria sido começada, sem ter sido terminada. Há duas vantagens para esta hipótese: o porticus Boni Euentus corresponde grosso modo à localização referida pela Vita Alexandri; as medidas avançadas para a basílica cabem no stagnum Agrippae. Há, no entanto, também um problema: Amiano Marcelino situa a construção do porticus Boni Euentus apenas em 374, cerca de 150 anos depois de Severo Alexandre ${ }^{(54)}$. 
É, no entanto, exequível que esta construção de 374 se tenha feito sobre uma estrutura inacabada ou apenas planeada dos Severos.

A área do lago de Agripa era certamente apetecível para quem quisesse construir de raíz um edifício no Campo de Marte: os horti e o stagnum Agrippae constituíam um espaço que, apesar de agradável, estava relativamente «livre». É também perfeitamente possível que, na época de Severo Alexandre, se tenham começado a lançar os fundamentos da nova basílica, o que justificaria os cálculos precisos fornecidos pela Vita Alexandri. A própria expressão da Vita Alexandri, "quam efficere non potuit», mostra que a basílica não foi concluída, mas supõe que terá sido começada. É também possível que Cláudio, o praefectus urbis que mandou construir o porticus Boni Euentus, tenha recuperado no século IV planos mais antigos. De qualquer modo, pelo menos o projecto da basílica de Severo Alexandre é verosímil, e é provável que a área destinada à sua construção possa ter sido o espaço livre do lago de Agripa, ainda para mais logo a sul das termas alexandrianas, paredes meias com os Seapta. Ora, esta proximidade permitiria dar coerência à intervenção de Severo Alexandre na região. De facto, uma basílica daquela dimensão poderia ter sido projectada para qualquer outro local da Cidade, com espaços eventualmente mais amplos e abertos em termos urbanos. Mas não: apesar de sobrelotado, terá sido o Campo de Marte o espaço eleito por Severo Alexandre para construir uma monumental basílica, acotovelada no meio dos edifícios patrocinados por Agripa, a poucos quarteirões dos templos, altares e colunas dedicados aos divinizados Antoninos. Severo Alexandre ombreava assim com os seus 'melhores' antecessores não apenas na monumentalidade da construção, apenas comparável com a Basílica de Trajano (não será por acaso que Severo Alexandre também intervirá extensivamente na área dos fora imperiais, em óbvia emulação com Nerva e Trajano(55)), como também na própria escolha do espaço para a sua edificação.

De resto, julgo que podem não ter ficado ainda por aqui as intervenções urbanas de Severo Alexandre no Campo de Marte. De acordo com a Vita Alexandri, o imperador interveio na ornamentação de um Iseum e de um Serapeum (SHA Alex. 26.8). O anónimo da Historia Augusta não esclarece a que templos destas duas divindades se está a referir: de facto, apenas Ísis possuía mais de dez templos em Roma. H. G. Ramsay listou as várias possibilidades para esta intervenção de Severo Alexandre ${ }^{(56)}$ : menciona por exemplo o(s) pequeno(s) templo(s) de Ísis e de Serápis no Monte $\mathrm{Cé}{ }^{\left({ }^{(57)}\right.}$ e o monumental tem- 
plo de Serápis no Quirinal. Este, no entanto, não era um templo dedicado especificamente a Ísis ${ }^{(58)}$.

No Campo de Marte, no entanto, existiam na época de Severo Alexandre precisamente um Iseum e um Serapeum, na proximidade um do outro, naquele que constituía o maior complexo religioso nilota em Roma ${ }^{(59)}$; ainda para mais, como admite Ramsay, "associated with imperial patronage - not only in the matter of restoration after burning, but in the matter of cultivating the favor of the goddess by featuring the shrine upon a coin "(60). De facto, presente em Itália desde pelo menos o século III a. C., após várias vicissitudes ${ }^{(61)}$ o culto de Ísis acabara por 'se romanizar', e merecera talvez primeiro com César e depois sobretudo com Calígula e com Domiciano (Eutr. 7.23, Hier. chron. s.a. $89 \mathrm{Helm}$ ) a dignidade de ter o seu santuário em pleno Campo de Marte, ao lado dos Saepta. Associado ao Iseum encontrava-se a sul um Serapeum mais pequeno, mas que, com o Iseum, transpunha para Roma o ambiente egípcio, no meio de alamedas ladeadas por imagens dos deuses nilotas, precisamente a sul do templo que Antonino Pio dedicará mais tarde a Adriano.

Mas, a ser assim, não entraria Severo Alexandre em contradição com a imagem tradicional que terá querido construir, aproximando-se do mundo orientalizante de Heliogábalo? Naturalmente, esta é uma inferência possível; contudo, não necessária. É verdade que ísis não era propriamente uma deusa tradicional de Roma. Mas era antiga. E, sobretudo, era francamente popular. Em outra ocasião(62), já procurei mostrar que estas devoções de matriz oriental não eram propriamente causa de escândalo na Roma do século III, nem para a plebe urbana nem sequer para um senado que se abrira às províncias e sobretudo ao Norte de África e ao Oriente. Que o culto a uma deusa como Ísis não seria em nada chocante, prova-o o facto de o maior dos seus santuários ser precisamente este no Campo de Marte, em pleno coração ideológico do principado. De facto, este Iseum do Campo de Marte encontrava-se numa zona "tradicional», sem que eu conheça qualquer animosidade contra ele depois do principado de Tibério (Joseph. Ant. lud. 18.3.4, Tac. ann. 2.85, Suet. Tib. 36). E, apesar de Ísis contar, entre os seus mais dedicados fiéis, com imperadores excêntricos e de tradição negativa como Calígula ${ }^{(63)}$, Otão (Suet. Oth. 12.1), Domiciano (Suet. Domit. 1.2), Cómodo (SHA Comm. 9.4, Pesc. Nig. 6.9) e Caracala (SHA Carac. 9.10), pelo contrário, não consta que tenha sido uma deusa da devoção de Heliogábalo. De resto, julgo que a ornamentação do Iseum e do Serapeum (como a possível inter- 
venção no templo sírio do Transtevere(64) ${ }^{(64)}$ deve vir na linha das restantes intervenções em templos dedicados a Júpiter ou a Vesta ${ }^{(65)}$, também levadas a cabo por Severo Alexandre. De facto, a ornamentação do Iseum e do Serapeum constituía antes de mais acto de pietas. As moedas confirmam que, depois do impius Heliogábalo, este era um dos tradicionais tópicos ideológicos que figuravam nas espécies monetárias do novo príncipe ${ }^{(66)}$.

É, pois, possível que, ao restauro e renomeação das termas de Nero, à construção e nomeação de um novo aqueduto, ao projecto e talvez início da construção de uma enorme basílica na mesma região, se tenha juntado a ornamentação destes templos campenses das divindades egípcias. Se os templos de Ísis e de Serápis em que Severo Alexandre interveio tiverem realmente sido estes do Campo de Marte, confirma-se o particular interesse do príncipe pela região. Se a estas intervenções se acrescentarem ainda as obras do estádio (sobre o qual se moldou a actual Piaza Navona), pela mesma data em que se reconstruíam as termas de Nero, então todo o conjunto que vai desde a actual Via delle Coppele a norte, ao Corso Vittorio Emanuele a sul, da Via dell'Anima a Ocidente até próximo da Via del Corso a Oriente pode ter sido alvo de obras ou de projectos durante o principado de Severo Alexandre, sem que eu tenha encontrado notícia de uma qualquer necessidade de intervenção geral na região.

Não é obviamente estranho que um qualquer imperador patrocine obras públicas em Roma, entre restauros e projectos/construções de novos edifícios. Raro seria o contrário. Mas é mais invulgar esta concentração em determinada região, num único principado; e é ainda mais singular o facto de a região intervencionada ter sido o prestigiado Campo de Marte. Se estiver correcta a interpretação que aqui defendo, julgo poder aventar a possibilidade de uma significação ideológica por trás do interesse do imperador pela região. Ao intervir ou planear intervir no Campo de Marte, de forma até mais extensiva do que qualquer dos Antoninos, só comparável a Agripa e a Augusto, acomodando as suas obras na proximidade das deles e deixando o seu nome explicitamente associado a elas, Severo Alexandre procurava certamente não apenas a imitatio mas também a emulação. Na superação da presença dos Antoninos na região, Severo Alexandre pode, de facto, ter apontado ideologicamente para a rivalização com o próprio início do principado, quando César, Agripa e Augusto intervieram no Campo de Marte. De resto, as obras de Severo Alexandre ajustaram-se sempre a edificações da época júlio-claudiana: as termas de 
Nero, o lago de Agripa, eventualmente os templos promovidos por César e Calígula. Como referi acima, a própria intervenção dos Antoninos na área deve já ter tido este referente ideológico. Por isso, para Severo Alexandre, se são certamente os Antoninos o modelo imediato, pode ser o tempo de Augusto o referente mais longínquo.

Ora, na história do principado, esses eram claramente os tempos de ouro das próprias relações entre o senado e o príncipe. Como já referi, numa época em que a existência de um imperador era facto incontornável, as intervenções urbanas de Severo Alexandre num dos espaços de maior significação ideológica da Urbe augustano-antonina devem ter significado, simbolicamente, a opção por um modelo político tradicional, de respeito pelos mores e pelo equilíbrio de poderes entre o príncipe e o senado. De facto, não há qualquer contradição entre a senatorialização da imagem do príncipe e a eleição dos modelos augustano e antonino por parte de Severo Alexandre. Pelo contrário, aquela senatorialização implicava necessariamente, no contexto do principado, esta eleição: a escolha do Campo de Marte e a aproximação a Agripa-Augusto e aos Antoninos tranquilizava o senado e construía simbolicamente uma imagem - a do optimus princeps que a Kaisergeschichte e a Historia Augusta de tradição senatorial hão-de louvar.

Severo Alexandre sobe ao poder em circunstâncias excepcionais. Particularmente ligado ao imperador assassinado, escolhido pelos pretorianos como seu sucessor em circunstâncias obscuras, acabou por the caber, a ele e ao grupo de que se passou a rodear, juristas e senadores, duas tarefas: por um lado, desligar-se do antecessor; por outro, assumir uma nova imagem. Mas em Roma pouco se inventa: a recusa de algo implica sempre a recuperação de um outro que se procura imitar e emular. No caso de Severo Alexandre, vários seriam os exemplos de que nos poderíamos socorrer que mostram este duplo movimento de eliminação e de eleição de modelos. O Campo de Marte (ao qual se poderiam acrescentar o Palatino e os fora imperiais) constitui campo privilegiado de análise, quer por motivos quantitativos (foi aí que Severo Alexandre mais interveio) quer qualitativos. Na eliminação de Heliogábalo, não bastou a simples, mas quase corriqueira damnatio memoriae. Elegeu-se um passado para Severo Alexandre observar. Como para o seu antecessor Septímio Severo, o mundo dos Antoninos 
continuava a ser demasiado apetecível: mesmo recusando topicamente o seu nomen, foi com o exemplo dos Antoninos que Severo Alexandre e o seu entourage procuraram rivalizar - ao intervir extensivamente no Campo de Marte, refazendo, restaurando e modificando construções antigas, Severo Alexandre ajeitava as suas obras paredes meias com os monumentos dos Antoninos. Ao mesmo tempo, sobrepondo-se a estruturas dos primeiros tempos do Império e afeiçoando o seu nome ao lado do de Agripa e a escassas ruas do de Augusto assumia uma identidade com os primeiros Césares, em pleno Campo de Marte, que a partir de então passaria a acolher também a marca indelével de um dos Severos, ombro a ombro com os fundadores do principado. Nas intervenções do Campo de Marte, anuncia-se implicitamente o regresso aos tempos dourados de prosperidade e abundância daqueles nomes dos antigos príncipes, de regresso aos valores de antanho e de respeito pelos privilégios do senado. Perante isto, não podemos deixar de sorrir. Por ingenuidade ou confiança, pelo menos no curto prazo Severo Alexandre estava redondamente enganado.

\section{Notas}

(1) Dio 80.1.1-5.31 = Xiph. 356.6-357.9. Ainda assim, a imagem é largamente positiva, pois Cássio Díon exercera o consulado com o próprio príncipe em 229.

(2) Cf. sobre este texto a análise de C. BERTRAND-DAGENBACH, Alexandre Sévère et l'Histoire Auguste, Bruxelles, 1990: "L'Alexandre Sévère de l'HA [...] est bien éloigné de la réalité historique mais, plus qu'un reflet déformé de l'histoire, il est, à la manière d'Alexandre le Grand dans la renaissance de sa légende au IV ${ }^{\natural}$ siècle, l'empereur modele" (p. 120).

(3) É curioso que Herodiano seja o autor mais próximo de Severo Alexandre, e seja precisamente aquele que mais insiste nesta incompetência.

(4) Talvez o problema de BERTRAND-DAGENBACH, Alexandre Sévère, p. 137 tenha sido o de tentar arrumar as diversas fontes num stemma, ainda que provisório e sem significar necessariamente uma dependência directa entre elas. De resto, a autora deveria também ter marcado a Kaisergeschichte a que Eutrópio ou Aurélio Victor terão recorrido, mas que infelizmente perdemos. De qualquer modo, e além de apresentarem alguns traços mais negativos de Severo Alexandre, não percebo, por exemplo, o que mais têm de semelhante os textos de Zósimo ou de Herodiano; menos clara ainda é a possível relação entre Eutrópio, por exemplo, e Cássio Dion. De qualquer modo, estou de acordo quanto ao facto de existirem duas tradições na definição de Severo Alexandre como princeps. Não me parece é que uma delas possa ser catalogada como «desfavorável» como refere a autora belga, já que o conjunto das fontes arrumadas nesta categoria apresenta elementos claramente contrastantes, entre positivos e negativos. A única fonte inteiramente negativa para Severo Alexandre é a sátira de Juliano, Caesares, onde a referência àquele imperador ocupa apenas meia dúzia de linhas e obedece ao tom sarcástico de todo o texto.

(5) Cf. a boa análise de BERTRAND-DAGENBACH, Alexandre Sévère, pp. 125-138. 
(6) K. FUCHS, "Beiträge zur Kritik Herodians (IV.-VIII. Buch)", Wiener Studien 18, 1896,

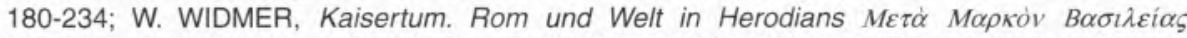

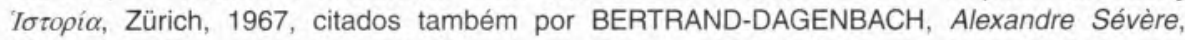
129. Pergunto-me se não será um pouco excessivo que toda a narrativa de Herodiano sobre a incompetência militar de Severo Alexandre obedeça à necessidade de justificar a subida ao poder de Maximimo, à qual o historiador dedica, é verdade, considerável atenção (Herod. 6.8). Admito que essa possa ser uma das possibilidades que levaram Herodiano a dedicar quase toda a biografia de Severo Alexandre às suas empresas militares, que, de facto, não ocuparam mais do que os últimos anos do seu principado. Contudo, com C. DÄNDLIKER, "Die drei letzten Bücher Herodians", Untersuchungen zur römischen Kaisergeschicte 3, Leipzig, 1870, 203-320, julgo que é possível, mesmo sem reduzir Herodiano a um mero compilador, anotar aqui a influência de duas fontes ou de duas tradições diferentes, já contemporâneas, acerca de Severo Alexandre.

(7) Como em outros trabalhos, por razões de clareza opto aqui por distinguir Elagábalo (a divindade) de Heliogábalo (o imperador), pese embora a homonímia nas línguas clássicas.

(8) As fontes do século IV preferem insistir na influência sobre Severo Alexandre dos conselheiros de origem senatorial, designadamente Ulpiano e Paulo (Eutr. 8.23, Aur. Vict. 24.6, SHA Alex. 26.5-6, 31.2-3, 34.6, 51.4, 67.2. Cf. também Dio 80.1.1, 80.2.2).

(9) Cf., sobre o Feriale Duranum, R. O. FINK, A. S. HOEY, W. F. SNYDER, «The Feriale Duranum", YCS 7, 1940, 1-222; e H. W. BENARIO, "The Date of the Feriale Duranum", Historia 11, 1962, 192-196.

(10) É certo que Herod. 5.7.1-2 refere que esta adopção fora induzida por Júlia Mesa, precisamente com medo de vir a perder o poder. Cf. também Dio 79.17.2-3. De acordo com uma das leituras do Feriale Duranum, a nomeação de Severo Alexandre como César aconteceu em 26 de Junho de 221. Não é normalmente aceite a versão da Historia Augusta que refere que o senado lhe conferira o título de César depois da morte de Macrino (SHA Elag. 5.1, Alex. 1.2). Eutr. 8.23 faz crer que a aclamação de Severo Alexandre como César teria sido obra do exército. Cf. M. HAMMOND, The Antonine Monarchy, Rome: Papers and Monographs of the American Academy, 1959, 13-14. Cf. C. R. WHITTAKER, Herodian in two volumes 2, London, Cambridge, Massachusetts: Willian Heinemann, Harvard University Press (Loeb Classical Library), 1970, 58-59, n. 1.

(11) CIL 6.3069 refere Heliogábalo e Severo Alexandre como imperatores a 1 de Junho de 221 (embora WHITTAKER, 1970, 58-59, n. 1, julgue tratar-se de um erro). AE, 1964, 269 e CIL 16.140, 141 referem também Severo Alexandre como imperator ainda antes da morte de Heliogábalo.

(12) WHITTAKER, 1970, 62, n. 2, defende que Alexandre foi considerado consors imperii, com um imperium minus. Cf. CIL 6.2001.

(13) R. FURTADO, «A que passado regressar? Reconfigurar e renomear o urbanismo em Roma na época de Severo Alexandre: o caso do Palatino", Espaço e paisagens. Antiguidade Clássica e heranças contemporâneas. VII Congresso Internacional da APEC (no prelo).

(14) R. FURTADO, "A que passado regressar?» (no prelo).

(15) Para uma boa síntese, veja-se W. ECK, «Emperor, senate and magistrates" in CAH 11, 214-237.

(16) Cf. a sintese de M. PEACHIN, "Rome the Superpower: 96-235 CE" in A companion to the Roman Empire. Ed. D. Potter, Oxford, Blackwell Publ., 2006, 149-151. Veja-se também A. WALLACE-HADRILL, "Ciuilis princeps: between citizen and king", JRS 72, 32-48 e o clássico mas sempre útil J. BÉRENGER, Recherches sur l'aspect idéologique du Principat, Verlag Friedrich Reinhardt ag Basel, 1953. 
(17) Cf. sobretudo Herod. 6.1.1-4, 6.1.6-7, SHA Alex. 6-12, 16, 18.1, 19, 21.3-5, 24.1, 30.1$-3,33.1,34,35.1-3,37.2-4,40-41,43.1-5$.

(18) Nem mesmo as moedas de Heliogábalo abandonam as principais uirtutes de matriz republicana: cf. R. FURTADO, “"Vinho novo em velhos odres". Porque foi assassinado Marco Aurélio Antonino?", Cadmo 17, 2007, 207-212.

(19) Cf. exemplos em B. CAMPBELL, "The Severan dinasty" in CAH 12, 22. Não são apenas as moedas que mostram esta auto-imagem do príncipe. Os rescritos que conhecemos proclamam a "pureza dos tempos" de Severo Alexandre (cf. CJ 9.9.9), mantendo como referente a «impureza" anterior.

(20) Cf. F. COARELLI, // foro romano, Roma, Quasar, 1986, 165; J. R. PATTERSON, «The city of Rome: from Republic to Empire", JRS 82, 1992, 194.

(21) Veja-se o excelente L. PIETILÄ-CASTREN, Magnificentia Publica: the Victory monuments of the Roman generals in the era of the Punic wars, Helsinki, Finnish Society of Sciences and Letters, 1987 (Commentationes Humanarum Litterarum, 84), 154-158, também citada por PATTERSON, "The city of Rome", 194. Cf. para todos estes monumentos, o já antigo, mas ainda sim fundamental S. B. PLATNER, T. ASHBY, A Topographical Dictionary of Ancient Rome, London: Oxford University Press, 1929; e ainda L. RICHARDSON JR., A new topographical dictionary of Ancient Rome, Baltimore, London, John Hopkins University Press, 1992; e sobretudo F. COARELLI, Guida archeologica di Roma, Verona, Arnoldo Mondadori Editore, 1974; F. COARELLI, I/ Campo Marzio: dalle origini alla fine della Repubblica, Rome, Quasar, 1997; e A. CLARIDGE, Rome. An Archaeological Guide, Oxford, Oxford University Press, 1998.

(22) Ainda na época de Augusto, encontramos o investimento no Campo de Marte por parte de homens próximos do príncipe, como L. Estatílio Tauro, que aí manda edificar o primeiro anfiteatro em Roma, em 29 a. C. (Dio 51.23.1; Suet. Aug. 29), e L. Cornélio Balbo, que inaugura em 13 a. C. o seu famoso teatro (Dio 54.25.2; Suet. Aug. 29). O anfiteatro de Estatílio Tauro foi destruído pelo incêndio de Roma, na época de Nero (cf. Dio 62.18.2).

(23) É certo que César não os concluiu. Lépido continuou a sua construção, que foi terminada por Agripa, a personagem que mais intervirá na região sul do Campo de Marte (cf. Dio 53.23.1-2). Veja-se o já antigo G. GATTI, «l Saepta lulia nel Campo Marzio», Urbe 2.9, sept. 1937, 8-23.

(24) Cf. P. ZANKER, Augusto y el poder de las imágines, Madrid, Alianza, 1992, 170-175.

(25) O templo deve ter sido concluído entre 27 e 25 a. C. (cf. CIL 6.896, Dio 53.27). O edifício foi restaurado por Domiciano (Hier. chron. s.a. 89 Helm). Cf. W. L. MACDONALD, The Pantheon: design, meaning and progeny, London, A. Lane, 1976.

(26) Trata-se do primeiro grande edifício termal público em Roma. Inaugurado em 25 a. C., no âmbito do extenso programa de obras públicas patrocinado por Agripa no Campo de Marte (Dio 53.27.1, 54.29.4).

(27) O stagnum Agrippae era um lago artificial ladeado pelos Horti Agrippae e mandado construir por Agripa a ocidente das suas termas (cf. Ov. ex Pont. 1.8.37-38, Strabo 13.1.19, Dio 54.29.4).

(28) Suet. Aug. 100, Strabo 5.8. Cf. P. ZANKER, Augusto, 97-102.

(29) Res gestae 12, Ov. fast. 1.709-722. Cf. sobretudo P. ZANKER, Augusto, 151-156, $208-$ -220, 241-244; K. GALINSKY, Augustan Culture, Princeton, Princeton University Press, 1996, 141-155; e P. F. ALBERTO, "O simbólico na construção da imagem e do programa ideológico de Augusto: os mitos de fundação da Cidade", Ágora 6, 2004, 27-50, com bibliografia na n. 7 (pp. 29-30). 
(30) Plin. NH 14.71, Amm. 17.4.12, ClL 6.702. Entre os artigos de E. Buchner, veja-se sobretudo E. BUCHNER, "De horologio solario Augusti”, Meander 42, 1987, 71-86.

(31) S. B. PLATNER, T. ASHBY, A Topographical Dictionary, 284, G. GATTI, "Topografia dell'Iseo Campense", Rendiconti della Pontificia Accademia Romana dell'Archeologia 20, 1943/4, 117-163; A. ROULLET, The Egyptian and egyptianizing monuments of Imperial Rome. Études préliminaires aux religions orientales dans l'empire romain (EPRO) 20, Leiden: Brill, 1972; F. CASTAGNOLI, "Influenze Alessandrine nell'urbanistica della Roma augustea", Rivista di filologia 109, 414-23.

(32) Suet. Nero 12, Caes. 5, Eutr. 7.15, Hier. chron. s.a. 63 Helm. Construídas provavelmente entre 62 e 64 d.C. Cf. G. GHINI, "Terme Neroniano-Alessandrine", Roma, Archeologia nel centro. 2. La città murata, 1985, 395-399.

(33) Suet. Dom. 5, Eutr. 7.23, Hier. chron. s.a. 89 Helm. Cf. A. M. COLINI, Stadium Domitiani, Rome, Reale Istituto di studi romani, 1943. É possível reconhecer ainda hoje o estádio de Domiciano sob o urbanismo da Piazza Navona.

(34) Situava-se a sul do estádio. Cf. S. B. PLATNER, T. ASHBY, A Topographical Dictionary.

(35) SHA Hadr. 19.10. No caso do Panteão, o restauro do edifício na época de Adriano (126 d.C.) deve ter sido uma autêntica reconstrução, ao ponto de o edifício guardar muito pouco da época de Agripa. É possível que esta reconstrução tenha sido apenas terminada por Antonino Pio (cf. SHA Pius 8.2). CIL 6.896 refere um novo restauro do panteão em 202. Também as termas de Agripa foram aumentadas na mesma época.

(36) Este templo foi dedicado em 145 (cf. SHA Pius 8.2), e encontra-se hoje sob a Borsa italiana, na Piazza di Pietra. L. COZZA, Tempio di Adriano, Rome, De Luca, 1982.

(37) Cf. CIL 6.1004. Situava-se na Piazza di Monte Citorio. Sobre o altar, há menos indicações, mas é possível que se identifique com o ustrinum Antonini Pii et Faustinae. Cf. S. B. PLATNER, T. ASHBY, A Topographical Dictionary, 131.

(38) Aur. Vict. 16.14, CIL 6.1585. Ainda hoje é possivel admirar esta coluna, óbvia emulação à coluna de Trajano, na Piazza Colonna. Pelo contrário, desconhece-se actualmente a localização deste templo de Marco Aurélio e Faustina.

(39) Cf. H. W. BENARIO, "Rome of the Severi», Latomus 17, 1956, 714-720 (para os principados de Septímio Severo, Caracala e Heliogábalo).

(40) F. COARELLI, "La situazione edilizia di Roma sotto Severo Alexandro", L'Urbs: espace urbain et histoire (ler siècle av. J.-C.- Ille siècle ap. J.-C.). Actes du colloque international (Rome, 8-12 mai 1985). Rome, 1987, 444: «il intervento più massiccio che ci è possibile ancora oggi controllare sul terreno è quello realizzato nell'area centrale del Campo Marzio, in prossimità del Pantheon".

(41) Cf. Mart. 2.48.8, 3.25.4, 7.34.5, 7.34.9, 12.83.5, Suet. Nero 12, Philostr. vit. Apoll. 4.42; Stat. Silu. 1.5.62, Caes. 5.3, Eutr. 7.15, Hier. chron. s.a. 63 Helm, ClL 6.8676, 9797.5. Cf. Cass. chron. 681, 920 (MGH. AA. chron. min. 2, 138, 146).

(42) Sobre estas moedas, vejam-se as notícias de H. G. RAMSAY, "A third century a. C. building program", $A C 4,1935,434$.

(43) Oxyrh. Pap. 3.412, 59ff. Cf. também Eutr. 7.15, SHA Alex. 25.3-4. Hier. chron. s.a. 227 Helm e Cass. chron. 920 (MGH. AA. chron. min. 2, 146) situam em 227 esta mudança do nome das termas de Nero. É possível que, no entanto, Neronianae tenha sido uma designação que se manteve também até época tardia: Sid. Apoll. carm. 23.495, Cass. Var. 2.39, CIL 6.3052. 
(44) Cf. G. CHINI, "Terme Neroniane-Alexandrine» in Roma: archeologia nel centro. 2. La città murata, Roma, De Luca, 1985, 395-399; L. RICHARDSON JR., New topographical dictionary, 393-395.

(45) A. CLARIDGE, Rome, 209.

(46) Cf. S. W. STEVENSON, A dictionary of Roman coins, London, George Bell, 1889, 790.

(47) STEVENSON, A dictionary, 790.

(48) No próprio edifício das termas ou entre as termas e o Panteão, Júlio Africano deve ter mandado construir um espaço para uma biblioteca, a chamada Bibliotheca Panthei. Cf. POxy. 3.39, $n^{\circ} .412$.

(49) Cf. L. RICHARDSON JR., A new topographical dictionary, 15.

(50) Cf. S. B. PLATNER, T. ASHBY, A Topographical Dictionary, 72, que diz que o passo da Historia Augusta se deve inspirar em Cic. ad Att. 4.16.8 Cic. ad Att. 4.17.7, sobre a construção dos Saepta e de um pórtico, com um comprimento de mil passos. De qualquer modo, parece-me, neste caso, uma inspiração muito duvidosa.

(51) Cf. F. CASTAGNOLI, "ll Campo Marzio nell'antichità", Memorie dell'Accademia Nazionale dei Lincei 8.1, 1947, 182-185.

(52) COARELLI, "La situazione edilizia di Roma», 441. Cf. S. B. PLATNER, T. ASHBY, A Topographical Dictionary, 420-421.

(53) Cf. S. B. PLATNER, T. ASHBY, A Topographical Dictionary, 420.

(54) Amm. 29.6.19. COARELLI, "La situazione edilizia di Roma", 442 considera que esta construção do porticus Boni Euentus tenha resultado, de facto, do "restauro de un monumento piú antico".

(55) Cf. R. FURTADO, «De novo Severo Alexandre e o urbanismo da Urbe: imitação e emulação nos fora imperiais" (no prelo).

(56) H. G. RAMSAY, "A third century a.C. building program", $A C 5,1936,147-156$.

(57) Cf. S. B. PLATNER, T. ASHBY, A Topographical Dictionary, 285.

(58) CIL 6.570 assegura, de resto, que este templo do Quirinal foi também alvo do restauro de Severo Alexandre. Este templo de Serápis nos Jardins de Colonna, no Quirinal, fora mandado construir por Caracala e era o maior templo em Roma, com uma área que deve ter rondado os $16890 \mathrm{~m}^{2}$, contando com dependências. Sobre este templo, cf. E. NASH, Pictorial Dictionay of Ancient Rome, Tübingen, London, New York: Verlag Ernest Wasmuth, A. Zwemmer Lda., Frederick A. Praeger, 1961-2, 376-383.

(59) Juv. 6. 528-529, Apul. met. 11.26, Eutr. 7.23.5. Cf. S. B. PLATNER, T. ASHBY, A Topographical Dictionary, 283-284; G. GATTI, "Topografia dell'Iseo Campense", Rendiconti della Pontificia Accademia Romana dell'Archeologia 20, 1943/4, 117-163; A. ROULLET, The Egyptian and egyptianizing monuments of Imperial Rome. Études préliminaires aux religions orientales dans l'empire romain (EPRO) 20, Leiden: Brill, 1972; M. MALAISE, Les conditions de pénétration et de diffusion des cultes égyptiens en Italie, EPRO 22, Leiden: Brill, 1972, 221-228; F. CASTAGNOLI, «Influenze Alessandrine nell'urbanistica della Roma augustea", Rivista di filologia 109, 414-423; J. E. STAMBAUGH, "The functions of Roman temples", ANRW 2.16.1, 1978, 596; M. LE GLAY, "Sur l'implantation des sanctuaires orientaux à Rome", L'Urbs: espace urbain et histoire (ler siècle av. J.-C.- Ille siècle ap. J.-C.). Actes du colloque international (Rome, 8-12 mai 1985), Rome, École Française de Rome, 1987, 548-549; L. RICHARDSON JR., New topographical dictionary, 211-212; M. BEARD, 
J. NORTH, S. PRICE, Religions of Rome, vol. 1, Cambridge, Cambridge University Press, 1998, 250-1, 264-265.

(60) RAMSAY, "A third century a.C. building program", AC 5, 150-151.

(61) Veja-se sobretudo o episódio da tentativa de instalação do culto de ísis e Serápis no Capitólio (Dio 42.26.2).

(62) R. FURTADO, "Vinho novo em velhos odres"», 195-197.

(63) A. BARTOLI, "Tracce di culti orientali sull Palatino Imperiale", Rendiconti della Pontificia Accademia Romana dell'Archeologia 29, 1956/7, 16-21; A. ROULLET, The Egyptian and egyptianizing monuments, 47-48; J. E. STAMBAUGH, "The functions of Roman temples", 595.

(64) Cf. S. B. PLATNER, T. ASHBY, A Topographical Dictionary, 148; R. KRILL, "Roman paganism under the Antonines and the Severans", ANRW 2.16.3, 1984, 34-36; e P. L. VAN BERG, Corpus Cultus Deae Syriae, 2 vol., EPRO 28.1-2, Leiden, Brill, 1972.

(65) Cf. FURTADO, "A que passado regressar?" (no prelo).

(66) Cf. RIC Alex. 3 (=RSC 198), 170. A primeira moeda é ainda da época em que Severo Alexandre é César, ainda em vida de Heliogábalo. Em ambas as moedas, a epígrafe é PIETAS AVG(usta). De qualquer modo, este tópico ideológico fora também utilizado por Heliogábalo. Cf. FURTADO, "Vinho novo em velhos odres"», 208. 